\title{
Voltaire, La Bible enfin expliquée, édition critique par Bertram Eugène Schwarzbach
}

\section{Michèle Bokobza Kahan}

\section{(2) OpenEdition}

\section{Journals}

Édition électronique

URL : http://journals.openedition.org/studifrancesi/459

DOI : 10.4000/studifrancesi.459

ISSN : 2427-5856

Éditeur

Rosenberg \& Sellier

\section{Édition imprimée}

Date de publication : 1 avril 2015

Pagination : 150-151

ISSN : 0039-2944

\section{Référence électronique}

Michèle Bokobza Kahan, «Voltaire, La Bible enfin expliquée, édition critique par Bertram Eugène Schwarzbach », Studi Francesi [En ligne], 175 (LIX | I) | 2015, mis en ligne le 01 avril 2015, consulté le 18 septembre 2020. URL : http://journals.openedition.org/studifrancesi/459 ; DOI : https://doi.org/ 10.4000/studifrancesi.459

Ce document a été généré automatiquement le 18 septembre 2020

\section{(c) $($ ) $\odot \odot$}

Studi Francesi è distribuita con Licenza Creative Commons Attribuzione - Non commerciale - Non opere derivate 4.0 Internazionale. 


\title{
Voltaire, La Bible enfin expliquée, édition critique par Bertram Eugène Schwarzbach
}

\author{
Michèle Bokobza Kahan
}

\section{RÉFÉRENCE}

VOLTAIRE, La Bible enfin expliquée, édition critique par Bertram Eugène SCHWARZBACH, Oxford, Voltaire Foundation, 2012 («CEuvres complètes de Voltaire» 79A, I, II), pp. 828.

1 Voici dans le cadre de l'édition critique des «Euvres complètes de Voltaire», La Bible enfin expliquée, l'un des trois derniers ouvrages que le patriarche de Ferney a consacrés à un commentaire critique de la Bible. Composé de deux volumes, l'ouvrage se trouve désormais à la disposition du lecteur. Le premier volume contient le texte voltairien présenté par une introduction d'une centaine de pages; le second déploie, sur plus de 300 pages, un appareil critique d'annotations dont l'ambition majeure est de situer Voltaire dans l'histoire des études bibliques. Sans aucun doute, le pari a été tenu.

Publiée en 1776, La Bible enfin expliquée n'est pas seulement un ouvrage de polémique anti-chrétienne qui se rajoute au répertoire voltairien à l'instar de textes comme le Sermon des cinquante ou à l'Examen important. À cette date, le philosophe avait atteint l'apogée de sa gloire, et cet ouvrage avait d'autres aspirations que la publication d'un énième pamphlet antireligieux. Dans la Bible enfin expliquée, Voltaire veut reprendre le modèle formel du Commentaire littéral de Dom Calmet. Cet ouvrage est la référence première de Voltaire qui reconnaît volontiers sa dette envers le moine bénédictin sur lequel il écrit le commentaire suivant: «Rien n'est plus utile que la compilation de ses recherches sur la Bible. Les faits y sont exacts, les citations fidèles. Il ne pense point, mais en mettant tout dans un grand jour, il donne beaucoup à penser» (Catalogue alphabétique de la plupart des écrivains français du siècle de Louis XIV). Mais le naturel voltairien revient au galop, et le philosophe mécréant se détourne assez rapidement du 
modèle érudit. Il préfère entretenir une espèce de dialogue sporadique entre lui-même comme éditeur anonyme et ses créatures de fiction, les quatre "aumôniers du prince de*** qui figurent dans le titre de l'édition de Kehl. De fait, il s'agit d'un projet philologique qui cherche à mettre la Bible dans son contexte historique pour mieux renverser les conclusions du moine bénédictin, insérer des commentaires farfelus, proposer des traductions lacunaires, introduire des réflexions et des remarques provocatrices, recycler un bon nombre de textes déjà publiés, construire un tissu de renvois à ces propres ouvrages comme à ceux d'autres auteurs.

Afin d'éclairer un peu mieux le problème des sources, B.E. schWARZBACH aborde la question de l'exégèse biblique voltairienne sous l'angle du processus d'écriture de la Bible enfin expliquée. Il semble assez probable que le philosophe ait introduit dans cet ouvrage tardif une quantité d'écrits et de brouillons qu'il avait dans son portefeuille et qu'il n'avait jamais publié auparavant exactement sous cette forme. Mais la conjecture d'une composition systématique de morceaux rédigés à des moments différents dans la vie du philosophe et conservés dans son portefeuille est finalement rejetée. L'hypothèse d'un travail effectué entre 1774 et 1776, qui perdrait en cours de route ses premières énergies philologiques semble plus plausible. Cela expliquerait en partie le fait que l'entreprise soit loin d'être aboutie. Les déficiences révèlent sans doute la difficulté d'un écrivain et philosophe comme Voltaire à se transformer en exégète érudit. Pour B.E. Schwarzbach, l'une des raisons de l'accueil plutôt froid des premiers lecteurs de la Bible enfin expliquée réside dans cette incohérence formelle de l'ouvrage.

4 À cette première incohérence se rajoutent les libertés prises par un philosophe enchanté de subvertir l'autorité des sources, surtout lorsque le but est d'«écraser l'infâme». Selon B.E. Schwarzbach, la diversité des références auctoriales que Voltaire attribue à ses multiples notes qui deviennent au fil du commentaire de plus en plus riches et originales sont pour la plupart fantaisistes. Voltaire exploite ces sources pour mener une critique des écritures saintes, noter les fautes, repérer les incohérences qui trahissent une fusion de sources. Mais son objectif n'est pas de réviser les erreurs scientifiques et éthiques qu'il a découvertes dans les textes bibliques à la suite de l'identification de contradictions internes. La valeur scientifique de la Bible est mise à mal par le philosophe qui s'emploie à identifier les contradictions, les faits invraisemblables et les anachronismes dans les récits bibliques, pour désacraliser un texte dont il reconnait en partie l'historicité mais dont il refuse de reconnaître l'autorité théologique et morale. À ce propos, les passages de l'introduction consacrés à la présentation de l'entreprise philologique de rabbins $\mathrm{du} \mathrm{xvI}^{\mathrm{e}}$ siècle comme Eliyahu Ashkenasi (1469-1549) qui tentent d'établir l'âge de composantes du/des texte(s) biblique(s) et les milieux dans lesquels ils avaient été rédigés à partir de manuscrits massorétiques, ainsi que la présentation des critiques et paléographes chrétiens comme Louis Cappel et Johann Heinrich Michaëlis (1668-1738), et tous ceux qui continuent le chemin tracé par les rabbins, ces pages jettent une lumière sur le domaine des recherches bibliques que les non-spécialistes fréquentent rarement; elles sont pour cette raison les bienvenues dans la mesure où elles permettent d'élargir l'horizon polémique et de le complexifier.

5 Les annotations de l'édition présente visent à identifier tous les passages bibliques ou historiques que Voltaire commente ou résume. Leur objectif second est de suivre Voltaire dans sa lecture de Dom Calmet qui est, on l'a dit, sa source d'érudition principale. De plus, B.E. Schwarzbach, responsable de l'édition critique des Examens de 
la Bible de Mme du Châtelet (Honoré Champion, 2011) a mené dans cet ouvrage une analyse comparée du texte de la marquise et du commentaire de Voltaire, ce qui permet d'éclairer la question de la dépendance mutuelle de ces deux corpus qui sont parallèles mais semblent généralement indépendants. Enfin, cette édition critique élargit le champ des études bibliques en s'attachant à identifier les exégètes juifs médiévaux et les exégètes de la Contre-Réforme qui avaient posé en leur temps les mêmes questions que Voltaire poserait entre 1762 et 1776. L'effort fourni pour déplisser de manière les méandres intertextuels ténus du commentaire biblique voltairien offre au lecteur une synthèse érudite de la littérature critique sur la religion avant la Révolution française. 